\title{
EDUCATION
}

\section{Critical Thinking as a Predictor of Certification Exam Performance in Medical Laboratory Science}

\section{BROOKE L. SOLBERG}

\begin{abstract}
The purpose of this study was to examine the value of critical thinking skills in predicting American Society for Clinical Pathology (ASCP) Board of Certification (BOC) exam scores for the Medical Laboratory Science (MLS) category. Existing data for undergraduate students in an accredited MLS program during the years of 2009-2012 were examined. Specifically, scores from a Critical Thinking Exercise (CTE) administered during the application process, along with Grade Point Average (GPA), Science Grade Point Average (SGPA), and ASCP BOC exam and subsection scores were analyzed. Results suggest that the CTE is a weak to negligible predictor of ASCP BOC exam performance $(r=0.113)$, while GPA and SGPA are stronger, statistically significant predictors $(r=0.358 ; \quad r=0.428 ; \quad p<.05)$. Although critical thinking skills did not significantly predict ASCP BOC exam scores, other implications for their predictive utility exist and are discussed in light of the findings from this and other existing studies within the health professions.
\end{abstract}

ABBREVIATIONS: MLS-medical laboratory science/ scientist; ASCP-American Society for Clinical Pathology; BOC-Board of Certification; NAACLSNational Accrediting Agency for Clinical Laboratory Sciences; GPA-Grade Point Average; CTE-Critical Thinking Exercise; SGPA-Science Grade Point Average; NCLEX-RN-National Council Licensure ExaminationRegistered Nurse

INDEX TERMS: Critical Thinking, Certification, Predictor, Medical Laboratory Science, GPA

Clin Lab Sci 2015;28(2):76

Brooke L. Solberg, PhD, MLS(ASCP) ${ }^{C M}, 501 N$. Columbia Road Stop 9037, UND SMHS Department of Pathology, Grand Forks, ND

Address for Correspondence: Brooke L. Solberg, PhD,
MLS(ASCP) ${ }^{C M}, 501$ N. Columbia Road Stop 9037, UND SMHS Department of Pathology, Grand Forks, ND 58202,701-777-224, brooke.solberg@med.und.edu

\section{INTRODUCTION}

The field of Medical Laboratory Science (MLS) demands an extensive understanding of challenging, complex information related to the field. Being a successful MLS practitioner, however, necessitates more than simply being aware of or able to recite these facts-it requires the ability to apply them in real-life troubleshooting situations. As a result, a major focus of MLS curricula often includes an emphasis on developing critical thinking skills.

While the need for MLS students to possess and utilize critical thinking abilities is obvious, it has yet to be studied whether such skills can help predict academic achievement, and more specifically, American Society for Clinical Pathology (ASCP) Board of Certification (BOC) exam success for the MLS category. As the National Accrediting Agency for Clinical Laboratory Sciences (NAACLS) has shifted to an outcomes-based focus with its revised standards, ${ }^{1}$ understanding the variables involved in predicting student success has become essential. Thus it is the intent of this study to provide MLS educators with evidence-based guidance related to the value of critical thinking skills, versus other more commonly studied cognitive measures, in predicting ASCP BOC exam performance.

Although not in MLS, the topic of certification/licensure exam predictors has been examined extensively by other health professions including but not limited to athletic training, ${ }^{2-5}$ chiropractic, ${ }^{6-7}$ dental hygiene, ${ }^{8-9}$ physical therapy, ${ }^{10-14}$ physician assistant, ${ }^{15-18}$ and nursing. ${ }^{19-22}$ While GPA is one of the most commonly analyzed academic prediction variables, $3,5,7-8,10-11,13-14,16-17,20,22-23$ these and other studies have considered additional factors such as standardized test scores (ACT, SAT, GRE, 
etc.), ${ }^{5,8,11,17,20,22}$ general demographics, ${ }^{3,17-18,22}$ pretest results, ${ }^{7,10}$ academic performance, ${ }^{7,16,18,22}$ clinical rotation duration and performance, ${ }^{3,14,18}$ psychological factors, ${ }^{2,11}$ and comprehensive program exam scores. ${ }^{14,16}$ Reviews of studies related to predicting success in health professions suggest that critical thinking skills are also an area of interest for analysis. ${ }^{24-25}$ Specifically, critical thinking abilities have been assessed for their value as a health science or medical program admission screening tool and in predicting academic and certification/licensure exam performance. ${ }^{9,12,17,21,26-30} \mathrm{~A}$ list of tools utilized in these studies for the quantitation of critical thinking are listed in Table 1.

Table 1. Common general critical thinking measures

\begin{tabular}{ll}
\hline CCTDI & California Critical Thinking Disposition Inventory \\
CCTST & California Critical Thinking Skills Test \\
CTPT & Critical Thinking Process Test \\
HSRT & Health Sciences Reasoning Test \\
PSI & Problem Solving Inventory \\
WGCTA & Watson-Glaser Critical Thinking Appraisal
\end{tabular}

Given the lack of research for both critical thinking skills and ASCP BOC predictors in MLS, it is the intent of the current study to fill that void by investigating the value of critical thinking skills at the time of MLS program admission in predicting ASCP BOC exam success. Additionally, a comparison of the predictive values for critical thinking vs. overall and science Grade Point Average (GPA) will be included. Based on the results of existing studies and the fact that it could be a rational supposition that individuals with greater critical thinking capabilities would perform better, it is hypothesized that critical thinking will predict ASCP BOC exam scores.

\section{MATERIALS AND METHODS}

Existing data were compiled from MLS program applications submitted during the years of 2009-2012 at a NAACLS accredited University-based program. Students completing the application were applying to the junior-level professional MLS program, and had already completed mandatory pre-requisite coursework. Only applications from students accepted by the program were reviewed. Data gathered from the applications included: 1) scores from a Critical Thinking Exercise (CTE) included in the students' application to the program; 2) overall undergraduate
GPA at the time of application to the MLS program; 3) GPA in undergraduate science coursework (SGPA) at the time of application to the MLS program; and 4) overall and subsection ASCP BOC exam scores. IRB approval for the study was granted by the hosting institution and data was analyzed using IBM SPSS Statistics 21 software.

\section{Critical Thinking Measure}

The CTE was developed to be utilized as one component of a diverse ranking system for initial MLS program applicants. The CTE consisted of a written passage with corresponding questions. The written passage pertained to an obscure laboratory procedure, in efforts to reduce the chance of applicants being able to find answers through other sources such as the internet. The questions were written in a way that forced the student applicant to do more than reply with word-forword information from the passage. For example, one question posed a scenario and asked the applicant to identify all instances in the scenario where the given procedure was not properly followed, along with an explanation of what the proper protocol would be. Applicants were instructed to respond to questions using only the information in the passage and to use complete sentences.

Each CTE was blinded and scored by two different MLS faculty members utilizing a specific rubric that evaluated the following components: response accuracy, grammar/sentence structure, ability to follow directions, and overall quality. The two faculty scores were averaged to give the applicant's final CTE score on a scale of 0 to 120 . Certain parameters were assigned predetermined deductions to ensure consistency. For instance, if verifiable evidence existed that an applicant had used outside resources on a particular item, he/she would receive zero points for that question. If a CTE was not submitted with the application, an overall score of zero was given. Note that applicants receiving a zero for this reason were not included in this study's dataset.

\section{Academic Measures}

Overall GPA was calculated based on all college-level coursework completed at the time of application submission. SGPA was calculated based on all collegelevel coursework related to science-biology, chemistry, biochemistry, anatomy, etc.-completed at the time of application submission. Overall ASCP BOC exam 
scores and subsection scores for the MLS category were collected from the ASCP Program Performance Reports provided to Program Directors for analysis of graduates' scores. Only scores from first time examinees that had applied to the MLS program between 2009 and 2012 were included in this study. ASCP granted permission for analysis of these results.

\section{RESULTS}

Data from 96 students was utilized in calculation of results. Of those students, $68(70.8 \%)$ were female and $28(29.2 \%)$ were male. Information related to age was not available in program applications, and thus results pertaining to age are not able to be reported.

Initial regression analysis for predictive value of CTE, GPA and SGPA revealed possible outliers based on visual analysis of the scatterplots. Cook's distance suggested that one point was having undue influence on each model, and thus it was eliminated from the dataset. Analysis after outlier removal indicated that the CTE was a weak to positive predictor $(r=0.113)$ of overall ASCP BOC scores, as illustrated by the scatterplot in Figure 1. Results showed that $1.3 \%$ of mean variance was explained by the model and the relationship was not statistically significant, $F(1,93)=1.21, p>.05$.

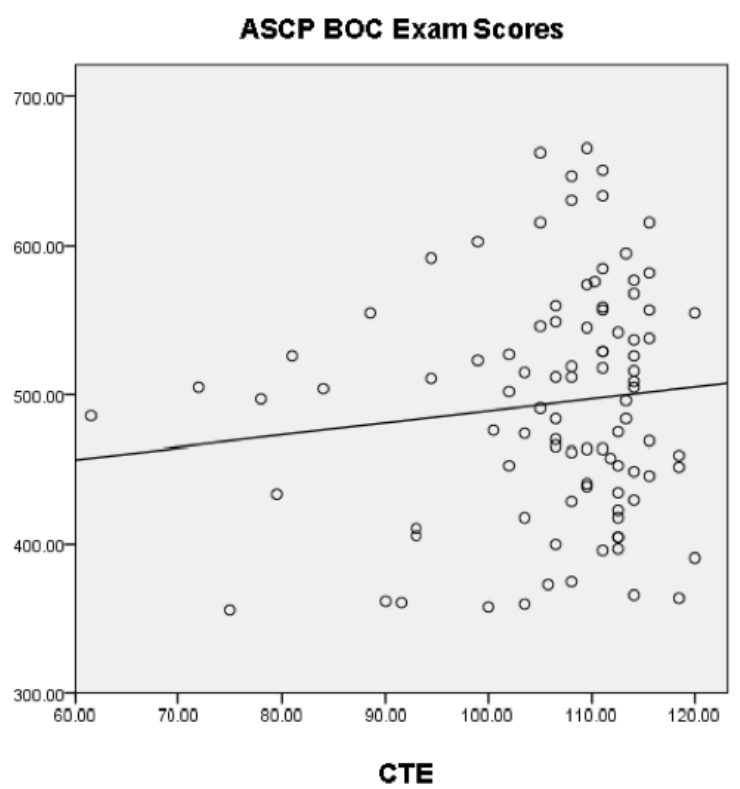

Figure 1. Curve estimation for CTE as a predictor of overall ASCP BOC exam scores $(r=0.113 ; p>.05)$.

GPA was found to be a moderate positive predictor $(r=0.358)$ of ASCP BOC performance. See Figure 2 for the correlating scatterplot. This relationship was statistically significant, $F(1,93)=13.63, p<.05$, with the model explaining $12.8 \%$ of mean variance. SGPA was also found to be a statistically significant moderate positive predictor $(r=0.428)$ of ASCP BOC performance, $F(1,93)=20.89, p<.05$, where $18.3 \%$ of mean variance was explained by the model. Figure 3 displays the scatterplot for this relationship.

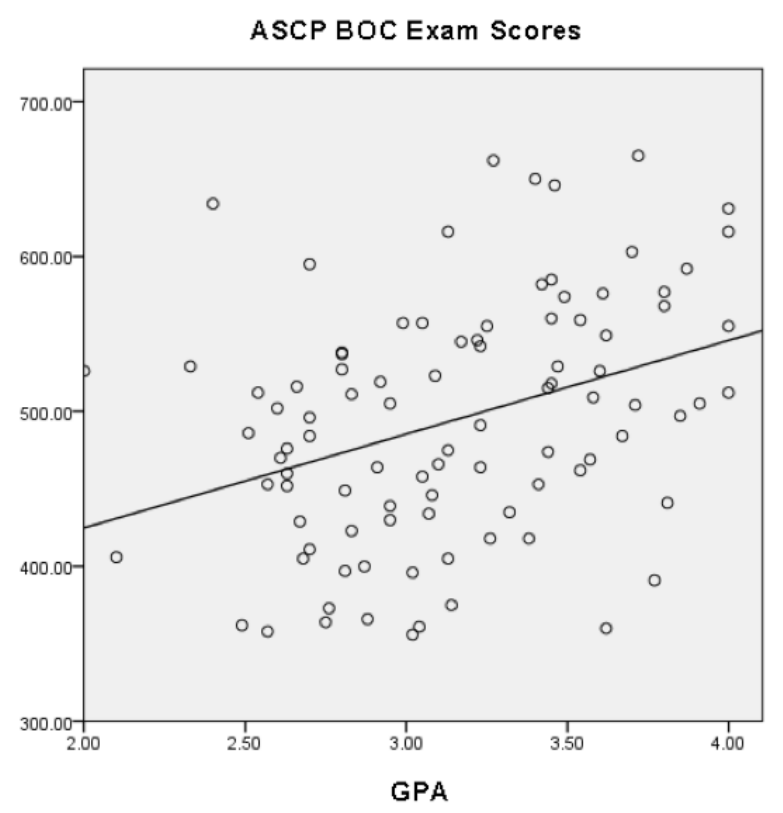

Figure 2. Curve estimation for GPA as a predictor of overall ASCP BOC exam scores $(r=0.358 ; \mathrm{p}<.05)$.

Along with overall scores, correlations were also examined for the following ASCP BOC exam subsections: Blood Bank; Chemistry; Hematology, Immunology, Lab Operations, Microbiology, and Urinalysis. A complete listing of these correlations is shown in Table 2. The CTE demonstrated weakly positive to negligible predictive value for all seven subsections, with no correlations being statistically significant. Overall GPA was a statistically significant positive predictor of all subsections except Immunology, Lab Operations, and Urinalysis. Similarly, SGPA was a statistically significant positive predictor of all subsections except Immunology and Lab Operations.

Mean comparative testing was performed to further dissect the relationship between the CTE and cognitive performance. The mean CTE score $(n=96)$ was 106.3 on a scale of 0 to 120 . Individuals receiving CTE scores above the mean $(n=66)$ had a mean ASCP BOC exam 
score of 497.3, while those with CTE scores below the mean $(n=30)$ had a mean ASCP BOC exam score of 480.1. When comparing overall ASCP BOC performance between these 2 groups, the difference was not statistically significant, $t(94)=-.970, p>.05$.

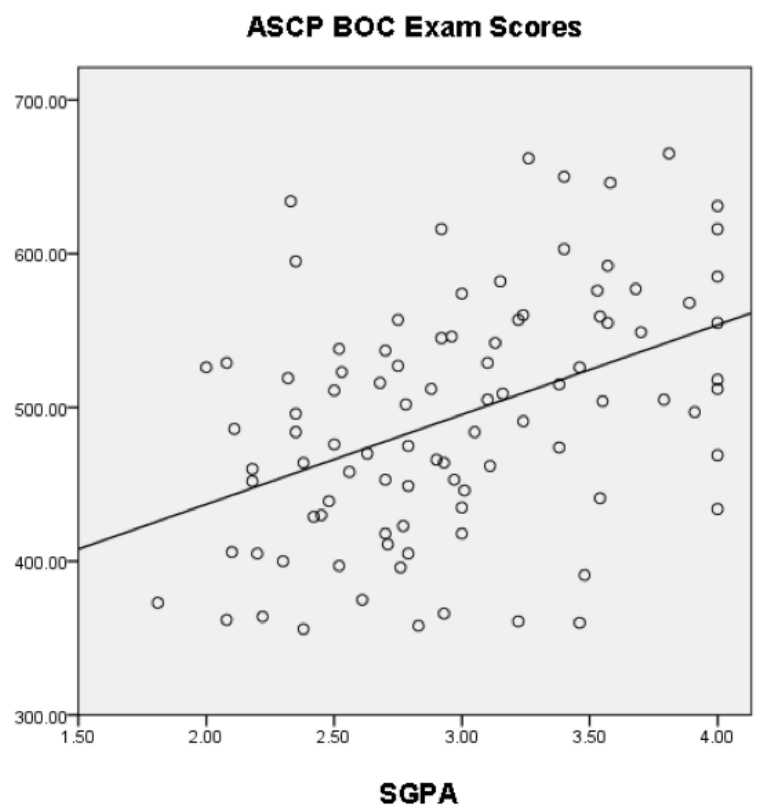

Figure 3. Curve estimation for SGPA as a predictor of overall ASCP BOC exam scores $(r=0.428 ; p<.05)$.

The mean CTE score for individuals passing the ASCP BOC exam on the first attempt was $106.5(n=83)$ versus $104.7(n=13)$ for those that failed the first attempt. The mean difference was not statistically significant, $t(94)=$ $.532, p>.05$. Individuals scoring above the mean on the ASCP BOC exam had a mean CTE score of 106.3 $(n=49)$, while individuals scoring below the mean had a mean CTE score of $106.2(n=47)$. Again, this difference was not statistically significant, $t(94)=.036, p>.05$.

The mean overall GPA was $3.14 \quad(n=96)$. The mean CTE score for those with overall GPA's $>3.14$ was $106.9(n=45)$ while the mean CTE score for those with overall GPA's of $\leq 3.14$ was $105.8 \quad(n=51)$. The mean difference was not statistically significant, $t(94)=.497$, $p>.05$. Similarly, the mean difference in CTE scores between those with SGPA's above the mean versus those with SGPA's equal to or below the mean was not statistically significant, $t(94)=.021, p>.05$, where the means were $106.31 \quad(n=45)$ and $106.27 \quad(n=51)$, respectively.

\section{DISCUSSION}

The main purpose of this study was to examine the predictive validity of critical thinking skills for ASCP BOC exam performance in the MLS category. Results suggest that critical thinking skills, as estimated by a CTE at the time of program admission, were weakly correlated $(r=0.113)$ with overall ASCP BOC exam performance and that the relationship was not statistically significant. Results for exam subsections mirrored this result, showing weak positive correlations for all seven areas $(r=0.029-0.175)$. While some existing investigations of critical thinking as a predictor of academic success have demonstrated similar results, ${ }^{27,28}$ others have produced slightly higher correlations than the findings here, ${ }^{12-13,30}$ including a meta-analysis of 41 published findings that revealed a moderate positive correlation $(r=0.31)$ for the aggregate. ${ }^{24}$

Table 2. Inter-item correlations summary

\begin{tabular}{|c|c|c|c|c|c|c|c|c|c|c|c|}
\hline & CTE & GPA & SGPA & ASCP & BB & $\mathrm{CH}$ & HE & IM & LO & MI & UA \\
\hline CTE & - & & & & & & & & & & \\
\hline GPA & .094 & - & & & & & & & & & \\
\hline SGPA & .011 & $.857^{*}$ & - & & & & & & & & \\
\hline ASCP & .113 & $.358^{*}$ & $.428^{*}$ & - & & & & & & & \\
\hline BB & .066 & $.273^{*}$ & $.312^{*}$ & $.699 *$ & - & & & & & & \\
\hline $\mathrm{CH}$ & .120 & $.247^{*}$ & $.273^{*}$ & $.740^{*}$ & $.328^{*}$ & - & & & & & \\
\hline HE & .029 & $.322^{*}$ & $.360^{*}$ & $.811^{*}$ & $.511^{*}$ & $.514^{*}$ & - & & & & \\
\hline IM & .175 & .175 & .161 & $.343^{*}$ & .165 & $.211^{*}$ & .180 & - & & & \\
\hline LO & .089 & -.011 & .016 & $.340^{*}$ & $.254^{*}$ & .182 & .056 & $.208^{*}$ & - & & \\
\hline MI & .077 & $.231^{*}$ & $.33^{*}$ & $.692^{*}$ & $.350^{*}$ & $.381^{*}$ & $.489^{*}$ & .154 & .137 & - & \\
\hline UA & .061 & .132 & $.220^{*}$ & $.455^{*}$ & $.230^{*}$ & $.318^{*}$ & $.283^{*}$ & -.107 & .184 & .197 & - \\
\hline
\end{tabular}

ASCP - overall ASCP BOC exam score (1st attempt; MLS category); BB-Blood Bank subsection; CH-Chemistry subsection; HE-Hematology subsection; IMImmunology subsection; LO-Lab Operations subsection; MI-Microbiology subsection; UA-Urinalysis subsection. *Significant correlation at the $\mathrm{p}<.05$ level. 


\section{EDUCATION}

A number of factors could be involved in the correlation discrepancy. First, many of the existing studies have focused on overall academic success as opposed to certification exam performance alone. Second, previous studies have analyzed health professions other than MLS. Third, the design of the CTE utilized in this study may not have been as robust as measures used elsewhere which resemble standardized tests. Similarly, the format of CTE used here-open-ended, short answer style questions-was not congruent with the testing format of the ASCP BOC exam. Lastly, in the current study, the CTE was administered upon application to the MLS program. Results from a CTE performed later, after the students' critical thinking skills had been given time to develop under program influence, would likely have showed a stronger correlation with ASCP BOC exam scores.

GPA is considered as a reliable, consistent predictor of academic success in the health professions. ${ }^{31}$ The results of this study corroborate that, with statistically significant moderate positive ASCP BOC exam predictive values for GPA $(r=0.358)$ and SGPA $(r$ $=0.428)$. These results compare with existing studies, where versions of GPA were shown to be significant and/or moderate to strong predictors $(r>0.300)$ of academic success. ${ }^{3,7,10-11,14,16,20,22}$

The fact that GPA and SGPA predict ASCP BOC exam performance more accurately than the CTE in this study is not necessarily surprising, when the format of the two variables is considered. The certification exam is a multiple choice style exam delivered through computer adaptive testing while the CTE was a shortanswer style assessment related to a single written passage. Had the two measures been congruent in style-for example the standardized multiple choice question HRST as a predictor of ASCP BOC scoresthe participants' strengths or weaknesses with the format, rather than with the content, would align and potentially result in higher correlations. Also, it should be considered that the type of critical thinking evaluated by the CTE in this study varies from that evaluated by the BOC exam.

The ASCP BOC exam for the MLS category is broken down into the following seven subsections, each related to major testing areas of the clinical laboratory: Blood Bank, Chemistry, Hematology, Immunology, Lab
Operations, Microbiology, and Urinalysis. Because each of these subsections constitutes a portion of the overall ASCP score, it is not surprising that subsection correlations with GPA and SGPA show similarities to the correlation values seen between those variables and overall ASCP score. SGPA showed greater predictive strength than GPA for all subsections except Immunology, likely because of the heavy science focus required for each of these topics. Of note, both GPA and SGPA were least correlated with the Lab Operations subsection. This could be explained partially because a large portion of the questions in the Lab Operations subsection pertain to hands-on, day-to-day experiences in the clinical laboratory-information learned and refined during clinical rotations. Although rotations are designed for equivalency between students, more variables exist due to the less controlled environment. For instance, a student with a high GPA may not have encountered certain troubleshooting situations during his/her clinical rotation, and likely would incorrectly answer those questions on the BOC exam regardless of his/her cognitive abilities.

Additional mean comparative testing was done to gain further insight into the role of the CTE as an ASCP BOC exam predictor. Results suggested that no significant mean differences were noted in BOC performance for those scoring either above or below the mean CTE value. There was no statistically significant difference between CTE scores for individuals passing versus failing the ASCP BOC exam, nor for those with BOC scores above or below the mean. Similarly, significant mean differences in CTE scores were not observed based on GPA's and SGPA's falling above or below the mean.

Again, this lack of correlation could be due to a disparity between the natures of critical thinking being analyzed. While the predictive strength of GPA and SGPA may lie in the cognitive comprehension domain as measured by a certification exam, the style of CTE utilized in this study may be more useful for predicting active troubleshooting abilities as seen in clinical practice. From that standpoint, a CTE could prove most valuable as a predictor of clinical success, which would be extremely beneficial for MLS programs trying to improve or maintain positive clinical outcomes.

Based on the findings of other studies, combining CTE 


\section{EDUCATION}

scores with other variables may help to increase the specificity of prediction for certain parameters. For example, Giddens and Gloeckner found that analyzing critical thinking skills (as measured by the CCTST and CCTDI) in conjunction with nursing GPA produced a 98\% accuracy rate in predicting who would pass the National Council Licensure Examination-Registered Nurse (NCLEX-RN). ${ }^{21}$ A study from DeAngelis showed that results from the PSI bolstered predictive value of both GPA and ACT score. ${ }^{29}$ Strengthening academic predictors by factoring in critical thinking abilities would be invaluable in MLS, where accreditation standards are now more heavily focused on outcomes.

\section{Limitations}

This study was performed by analyzing data from a single MLS program over the span of three years. Data from multiple programs over a longer period of time would help substantiate generalizability. There are also potential limitations with the CTE utilized in this study. First, completion of the CTE was part of the program application process, and therefore no regulatory guidelines could be enforced to assure that the applicant completed the CTE without assistance and within a given timeframe. For example, an applicant could have obtained aid from an advisor in completion of the CTE, resulting in a score that was not an accurate reflection of the applicant's actual critical thinking abilities. Also, the CTE scores were determined through subjective evaluation. Despite efforts made to standardize the grading process as much as possible-through utilization of a uniform rubric, blinded responses, and an average of two scorespotential still exists for error to be introduced from subjectivity.

\section{Future Applications}

Although the results of this study suggest that critical thinking skills as estimated by a CTE are not strong predictors of ASCP BOC exam performance, potential applications for critical thinking estimates still exist, and thus warrant further investigation. As previously discussed, critical thinking may be a valuable predictor of clinical/psychomotor performance in MLS, and as such deserves exploration. Also, as evidenced by studies in different professional areas, an analysis of critical thinking in connection with other more common admission variables such as GPA could yield the most robust predictors of academic success in MLS to date. An investigation of whether critical thinking influences another topic of interest in MLS education, student attrition, could provide enlightening results as this is an area with less conclusive existing findings. Finally, it would be interesting to look into the same outcome, ASCP BOC exam performance, but with a critical thinking measure that better matches the multiple choice format of the BOC exam, such as the CCTST or HSRT.

\section{CONCLUSION}

Critical thinking abilities are essential components of the MLS skillset. Estimating critical thinking in MLS students can provide valuable insight for facilitating student success in the profession. Although this study suggests that critical thinking abilities are not strong forecasters of MLS certification scores, they may well have worth in predicting clinical performance or in strengthening the predictive capacity of existing variables such as GPA. Assessment of critical thinking in future MLS professionals thus could be beneficial to educators and students alike, as improving academic outcomes is the ultimate goal for both.

\section{REFERENCES}

1. National Accrediting Agency for Clinical Laboratory Sciences. NAACLS Standards for Accredited and Approved Programs. 2014:1-84. Available from http://www.naacls.org/docs/stand ards2012.pdf

2. Breitbach AP, Downey DL, Frager AJ. The relationship between candidate psychological factors and first-attempt pass rate on the Board of Certification examination. Athl Train Educ J. 2013;8:10-6.

3. Middlemas DA, Manning JM, Gazzillo LM, Young J. Predicting performance on the National Athletic Trainers' Association Board of Certification examination from grade point average and number of clinical hours. J Athl Train. 2001;36(2):136-40.

4. Turocy PS, Comfort RE, Perrin DH, Gieck JH. Clinical experiences are not predictive of outcomes on the NATABOC examination. J Athl Train. 2000;35(1):70-5.

5. Harrelson GL, Gallaspy JB, Knight HV, Leaver-Dunn D. Predictors of success on the NATABOC certification examination. J Athl Train. 1997;32(4):323-7.

6. McCall AR, Harvey RD. Predictors of performance on the National Board of Chiropractic Examiners parts I and II. J Chiropr Educ. 2014;28(1)9-15.

7. Kenya AW, Kenya HM, Hart J. Correlation between academic performance and NBCE part I scores at a chiropractic college. J Chiropr Educ. 2013;27(1):27-32.

8. Ward ST, Downey MC, Thompson AL, Collins MA. Predictors of success in dental hygiene education: A follow-up study. J Dent Hyg. 2010;84(1):24-8. 


\section{EDUCATION}

9. Williams KB, Schmidt C, Tilliss TS, Wilkins K, Glasnapp DR. Predictive validity of critical thinking skills and disposition for the national board dental hygiene examination: A preliminary examination. J Dent Educ. 2006;70(5):536-44.

10. Sloas SB, Keith B, Whitehead MT. Use of a pretest strategy for physical therapist assistant programs to predict success rate on the National Physical Therapy Exam. J Allied Health. 2013;42(2):79-83.

11. Galleher C, Rundquist PJ, Barker DB, Chang WP. Determining cognitive and non-cognitive predictors of success on the National Physical Therapy Examination. Internet J Allied Health Sci Pract. 2012;10(4).

12. Aldridge RL Jr, Keith B, Sloas S, Mott-Murphree A. Relationship of the Nelson Denny Reading Test to scores on the National Physical Therapy Licensure Examination. J Allied Health. 2010;39(2):72-5.

13. Vendrely AM. An investigation of the relationships among academic performance, clinical performance, critical thinking, and success on the Physical Therapy Licensure Examination. J Allied Health. 2007;36(2):e108-23.

14. Kosmahl E. Factors related to physical therapist license examination scores. J Phys Ther Educ. 2005;19(2):52-6.

15. Brown G, Imel B, Nelson A, Hale LS, Jansen N. Correlations between PANCE performance, physician assistant program grade point average, and selection criteria. J Physician Assist Educ. 2013;24(1):42-4.

16. Ennulat CW, Garrubba C, DeLong D. Evaluation of multiple variables predicting the likelihood of passage and failure of PANCE. J Physician Assist Educ. 2011;22(1):7-18.

17. Higgins R, Moser S, Dereczyk A, Canales R, Stewart G, Schierholtz C, et al. Admission variables as predictors of PANCE scores in Physician Assistant programs: A comparison study across Universities. J Physician Assist Educ. 2010;21(1):10-7.

18. Oakes DL, MacLaren LM, Gorie CT, Finstuen K. Predicting success on the Physician Assistant national certifying examination. Perspect Physician Assist Educ. 1999;10(2):63-9.

19. Romeo EM. The predictive ability of critical thinking, nursing GPA, and SAT scores on first-time NCLEX-RN performance. Nurs Educ Perspect. 2013;34(4):248-53.

20. Grossbach A, Kuncel NR. The predictive validity of nursing admission measures for performance on the National Council Licensure Examination: A meta-analysis. J Prof Nurs. 2011; 27(2):124-8.

21. Giddens J, Gloeckner GW. The relationship of critical thinking to performance on the NCLEX-RN. J Nurs Educ. 2005;44(2):85-9.

22. Beeman PB, Waterhouse JK. NCLEX-RN performance: Predicting success on the computerized examination. J Prof Nurs. 2001;17(4):158-65.

23. Ortega KH, Burns SM, Hussey LC, Schmidt J, Austin PN. Predicting success in nurse anesthesia programs: An evidencebased review of admission criteria. AANA J. 2013;81(3):183-9.

24. Ross D, Loeffler K, Schipper S, Vandermeer B, Allan GM. Do scores on three commonly used measures of critical thinking correlate with academic success of health professions trainees? A systematic review and meta-analysis. Acad Med. 2013;88(5): 724-34.

25. Pitt V, Powis D, Levett-Jones T, Hunter S. Factors influencing nursing students' academic and clinical performance and attrition: An integrative literature review. Nurse Educ Today. 2012;32(8):903-13.

26. Kelsch MP, Friesner DL. The Health Sciences Reasoning Test in the pharmacy admissions process. Am J Pharm Educ. 2014;78(1):9.

27. Wilkinson D, Zhang J, Byrne GJ, Luke H, Ozolins IZ, Parker $\mathrm{MH}$, Peterson RF. Medical school selection criteria and the prediction of academic performance. Med J Aust. 2008;188(6):349-54.

28. Lobb WB, Wilkin NE, McCaffrey DJ, Wilson MC, Bentley JP. The predictive utility of nontraditional test scores for firstyear pharmacy student academic performance. Am J Pharm Educ. 2006;70(6):128.

29. DeAngelis S. Noncognitive predictors of academic performance. J Allied Health. 2003;32(1):52-7.

30. Scott JN, Markert RJ. Relationship between critical thinking skills and success in preclinical courses. Acad Med. 1994;69(11):920-4.

31. Salvatori P. Reliability and validity of admissions tools used to select students for the health professions. Adv Health Sci Educ Theory Pract. 2001;6(2):159-75. 